Research Article

\title{
Efficacy of physiotherapy for postural low back pain due to ligament stress and strain in a professional group of middle aged population
}

\begin{abstract}
The suffering and loss of working hours due to the disability caused by low back pain in develop and developing countries have been a constant stimulus for further research. It is a common problem and is increasing day by day in Bangladesh also and need to be studied. The underlying cause of back pain is usually undiagnosed and left untreated even though the diagnosis of ligament stress and strain can be made easily by clinical methods. The result of management of backache due to the ligament stress and strain treated conservatively by physiotherapy is now found to be satisfactory. Total 100 cases of ligament stress and strain in the lumber region were divided into three groups according to the variety of condition. Most of the cases were diagnosed on the basis of clinical assessment. X-ray of lumbar spine was done as a routine procedure of exclude other pathology. To evaluate the result, Physiotherapy management were carried out during the period of January 2014 to June 2014 in Islami Bank Central Hospital, Kakrail, Dhaka. There were 66 male and 34 female patients. Lowest age incidence was 30 years and highest was 55 years. The maximum number was in the age group of 35 to 45 years. 71 cases belong to manual working class and 29 belong to sedentary population. All the patients presented primarily with history of low backache with restricted movement and postural mal-alignment. The onset of pain was traumatic and was also lifting heavy objects. Physiotherapy treatment was carried out according to the severity of the condition. The method of physiotherapy treatment were rest in bed, posture care, cryo therapy, ultrasound therapy, wax pack therapy, intermittent lumber traction, mobilization, therapeutic exercise and home advice to reduce weight and overcome back pain. It was placed into three groups. Group- A: Acute, Group- B: Sub-Acute, Group- C: Chronic. In Group- A, we found 73\% patient responded very well followed by Group- B, 61\% patient responded satisfactory and in Group- C, 76\% responded excellent.
\end{abstract}

Keywords: Efficacy of physiotherapy, Postural low back pain, Middle aged population, Clinical Standards advisory group
Volume 3 Issue 5 - 2015

\author{
Monoarul Haque MD, ${ }^{3}$ Mohammad Shariful \\ Islam, ${ }^{2}$ Altaf Hossain Sarker,' Tarafder Nahid \\ Parveen $^{3}$ \\ 'Department of Physiotherapy, The Peoples University of \\ Bangladesh, Bangladesh \\ 2Department of Physiotherapy, Ibn Sina D, Bangladesh \\ ${ }^{3}$ Bangladesh Physiotherapy Association, Bangladesh
}

Correspondence: Md Monoarul Haque, Bangladesh Physiotherapy Association, 29 Probal Housing, Adabor, Shyamoli, Dhaka, Bangladesh, Tel 88 01915839550, Email monoarmunna@yahoo.com

Received: October 19, 2015 | Published: November 05, 2015

\section{Introduction}

Low back pain is widespread problem in recent years. ${ }^{1}$ It affects quality of life. ${ }^{2}$ Low back pain occurs in both sexes, but it is more common in adults with ages ranging from 30 to 50 years and it has been associated with increased health care expenditures. ${ }^{3}$ In the United States of America, about $50 \%$ of all people have already had an episode of low back pain. ${ }^{4}$ In the United Kingdom, the Clinical Standards Advisory Group (CSAG) of the British Ministry of Health found that 16.5 million people were affected by low back pain. ${ }^{5}$ In Germany, ${ }^{6}$ Turkey $^{7}$ and France ${ }^{8}$ the occurrences of low back pain were $59 \%, 51 \%$ and $55.4 \%$, respectively. A study in Bangladesh estimated that $78 \%$ of professional car drivers suffer from LBP. ${ }^{9}$ Ligament stress and strain is one of the very important causes of low back pain. This ligament stress and strain directly associated with daily activities. Its frequency and annual toll of suffering day by day seriously is stimulating to the people. Sometimes the sufferer keeps himself from out of work. The problem may be solved by advice and conservative treatment with physiotherapy. The problem may be also prevented by personal awareness, keeping posture erect and maintain strong back and abdominal muscles. As far we know, there has been no publication dealing with only physiotherapy management of low back pain due to ligament stress and strain for middle aged professional people in the country. So the physiotherapy management is very important for the said suffering people.

\section{Methodology}

1. Study Design: Experimental study design

2. Study Setting: Islami Bank Central Hospital, Kakrail, Dhaka

3. Study Population: Subjects with non-specific back pain were selected after due consideration of the inclusion and exclusion criteria

4. Study Duration: The study was conducted over a period of 6 months, from January 2014 to June 2014. Individual subjects underwent treatment duration of four weeks.

5. Population Size: Total of 100 subjects was included for the study by using random sampling method

\section{Criteria for Selection}

1. Inclusion criteria

2. Both sex included

3. Age group of 30 to 55 years

4. Occupation - Construction worker, Driver, House wife, Nurses, Office executive

5. Willing subjects 
6. Patients with postural low back pain

7. Patient with primary diagnosis of postural low back pain of between 6 to 26 weeks of duration

8. Exclusion criteria

9. Cardiovascular impairments

10. Severe disability

11.Trauma

12. Spinal surgery

13. Spondylolisthesis

14. Ankylosing spondylitis

15. Dysfunction and derangement syndrome

16. Procedure o f study

Subjects with postural back pain who visited the Outpatient Department of Islami Bank Central Hospital were selected by simple random sampling method. Patients who are meeting the inclusion and exclusion criteria were selected for this study. 100 patients with nonspecific back pain who fulfilled inclusion and exclusion criteria were selected and all the subjects were divided into 3 groups. Group -A (Acute stage, 33 subjects), Group -B (Sub-acute stage, 33 subjects), Group -C (Chronic stage, 34 subjects). Each patient provided physiotherapy treatment according to their assessment for two to four weeks and after completing treatment we recorded their improvement.

\section{Data analysis}

For data analysis descriptive statistics was used. Descriptive statistics are commonly used to make sense of survey data, where large quantities of information are collected. For this type of study, normally descriptive type of study is suitable for data analysis and presentation. Most of the data was nominal so for this reason data was presented by pie chart, bar chart, graph and table.

\section{Results}

Group A: Acute stage - Very recent cases (From 1st day of injury up to 3rd day) included in this group. Number of cases - 33 (Male - 23, female - 10)

Group B: Sub-acute stage - From 4th day of injury up to 2 weeks patients are included in this group. Number of cases - 33 (Male - 20, Female - 13)

Group C: Chronic stage - After 2 weeks of injury patients are included in this group. Number of cases - 34 (Male - 23, Female - 11)

Male Patient: 66 Female Patient: 34 Total Patient: 100 (Table 1).

\section{Group - A}

Acute stage

\section{Treatment modalities}

Rest in bed: Complete bed rest mostly in supine lying with a soft pillow under the head or without but a pillow must be put under both knee joint.

Posture care: As the patient remains in bed mostly in supine lying he/ she should turn in one piece when necessary.

Cryotherapy: Treatment with ice - crushed ice should be used by a wet towel over the lumber region not more than 15 minutes at one time; thrice in a day. Before applying ice, the part should be rubbed with olive oil to prevent ice burn.
Isometric exercise: The patient will contract the spinal and abdominal muscles and relax them without moving the spine.

$\mathrm{n}$ this group - A, we found around $73 \%$ of patients responded satisfactorily (Table 2).

\section{Total number of Cases - 33}

Table I Shows that out of postural low back pain due to ligament stress and strain patient male and female were $66 \%$ and $34 \%$

\begin{tabular}{lll}
\hline Sex & Frequency & Percentage \\
\hline Male & 66 & 66 \\
Female & 34 & 34 \\
Total & 100 & 100 \\
\hline
\end{tabular}

Table 2 Shows that about 73\% patient was satisfied followed by good result $15 \%$ and poor result $12 \%$

\begin{tabular}{ll}
\hline Number of Cases & Result \\
\hline 24 & Satisfactory - 73\% \\
5 & Good - 15\% \\
4 & Poor - 12\% \\
Total $=33$ & $100 \%$ \\
\hline
\end{tabular}

Table 3 Shows $61 \%, 27 \%$ and I2\% was satisfactory, good and poor

\begin{tabular}{ll}
\hline Number of Cases & Result \\
\hline 20 & Satisfactory - 61\% \\
9 & Good - 27\% \\
4 & Poor - 12\% \\
Total = 33 & $100 \%$ \\
\hline
\end{tabular}

Table 4 Shows that more than three-forth patients (76\%) responded excellent followed by satisfactory $15 \%$, good $6 \%$ and poor $3 \%$

\begin{tabular}{ll}
\hline Number of Cases & Result \\
\hline 26 & Excellent $-76 \%$ \\
5 & Satisfactory - I5\% \\
2 & Good $-6 \%$ \\
$\mathrm{I}$ & Poor $-3 \%$ \\
Total $=34$ & $100 \%$ \\
\hline
\end{tabular}

\section{Group - B}

\section{Sub-acute stage}

\section{Treatment modalities}

Rest in bed: Patient will remain in bed but the patient is allowed to sit up for a while with using corset and may also be allowed to go up to toilet during this period. Gradually rest period is lifted and the patient is allowed to walk.

Posture care: Patient will maintain erect posture of the spine in sitting and in standing as was in bed during rest period.

Wax pack therapy: Wax pack therapy is applied for 10 to 15 minutes twice daily to relief pain and stiffness.

Ultrasound therapy: Pulsed type of ultrasound therapy is applied to repair the tissues involved and relief pain and spasm. This should be applied with low dosage $\left(0.75 \mathrm{Watt} / \mathrm{cm}^{2} \times 7 \mathrm{~min}\right)$ twice daily for 5 days.

Isometric exercise: Patient is allowed to raise both legs alternately. Supine lying both knees bending - flexion of the hips, flexion of the head and shoulder. Then starting from five such bouts up to ten bouts. Prone lying - extension of the legs alternately and extension of head and shoulder starting as before. In this group - B, we found around $61 \%$ of patients responded satisfactorily (Table 3). 
Total number of cases -33

\section{Group - C}

\section{Chronic stage}

\section{Treatment modalities}

Rest in bed: Bed rest is minimized in this period. The patient is allowed to sit, to stand and to walk for a little distance then the distance is increased according to the patient's tolerance.

Posture care: Posture care should be observed as before. Patient should sit in a chair with an erect posture keeping back rested behind the back of the chair. No lifting, no pushing or pulling is allowed. Before sitting the patient should turn on his side at the edge of the bed, then sit up pushing on elbow. Patient should lie in the same way.

Ultrasound therapy: Ultra sound therapy is applied as before but the dose and time is increased and the frequency of application is decrease to once daily for two weeks. It is applied according to the patient's condition of deep seated pain and tightness of the tissues. The dosage should be $1.5 \mathrm{Watt} / \mathrm{cm}^{2} \times 10$ minutes for two weeks. Four cases required further one week's ultrasound therapy on alternate days for recovery of pain and stiffness.

Intermittent lumber traction: Intermittent lumber traction is given to get mobility of lumbar spine in case of stiffness and tightness of ligaments of the same region. Dosage should be as follows for twice daily for ten days. Tension $30 \mathrm{kgs}$ depending upon the patient's tolerance with 40 seconds hold time and 20 seconds rest time during traction. Traction should be continued up to four weeks on alternate days and twice weekly for the last week of treatment.

Mobilization of the lumbar spine: Specialized passive movement technique are used in prone lying and both side lying positions to mobilize the joints of lumber region which are restricted due to tightness of injured ligaments of lumbar spine. This is done on alternate days for 10 - 15 minutes once daily for three weeks.

Therapeutic exercise: Patient is being taught gradually the following exercises to be performed thrice daily. In supine lying flexion exercise of lumbar spine is started initially. Then extension exercise in prone lying and gradually side flexion and rotation exercise are included in different positions. As the patient is improving gradually difficult exercises are included. To strengthen the muscles of the lumber region, different type of resisted exercises are also given.

Activities: As the patient has already started the activities of daily living he/she should start swimming for about 10 15 minutes. As the patient has already started the household activities he/she should started playing different types of games according to the patient's tolerance and occupation. In this group- $\mathrm{C}$, we found around $76 \%$ of patients responded excellent (Table 4).

\section{Total number of cases - 34}

Success of treatment is almost $85 \%$ in age ranged between 30 years to 40 years. Success of treatment is almost $70 \%$ in age ranged between 40 years to 50 years. Success of treatment is almost $55 \%$ in age ranged between 50 years to 55 years (Figure 1).

\section{Discussion}

Low back pain affected the human being science time immemorial but little knowledge had been acquired about the way in which the injury of ligaments and muscles causes back pain. The key finding of the present study was efficacy of physiotherapy. We found physiotherapy with different techniques was effective in $85 \%$ cases age ranges from $30-40$ years. Gradually physiotherapy is becoming popular treatment in Bangladesh. Management of low back pain depends on which of the three general categories is the cause: mechanical problems, non-mechanical problems, or referred pain. ${ }^{10}$ For acute pain that is causing only mild to moderate problems, the goals are to restore normal function, return the individual to work, and minimize pain. The condition is normally not serious, resolves without much being done, and recovery is helped by attempting to return to normal activities as soon as possible within the limits of pain. ${ }^{11}$ Providing individuals with coping skills through reassurance of these facts is useful in speeding recovery. ${ }^{12}$ For those with sub-chronic or chronic low back pain, multidisciplinary treatment programs may help. ${ }^{13}$ Increasing general physical activity has been recommended, but no clear relationship to pain or disability has been found when used for the treatment of an acute episode of pain. ${ }^{14}$ For acute pain, lowto moderate-quality evidence supports walking. ${ }^{15}$ There is tentative evidence to support the use of heat therapy for acute and sub-chronic low back pain ${ }^{16}$ but little evidence for the use of either heat or cold therapy in chronic pain. ${ }^{17}$ Exercise therapy is effective in decreasing pain and improving function for those with chronic low back pain. ${ }^{18}$ It also appears to reduce recurrence rates for as long as six months after the completion of program ${ }^{19}$ and improves long-term function. There is no evidence that one particular type of exercise therapy is more effective than another. ${ }^{20}$ The Alexander technique appears useful for chronic back pain ${ }^{21}$ and there is tentative evidence to support the use of yoga. ${ }^{22}$ Transcutaneous electrical nerve stimulation (TENS) has not been found to be effective in chronic low back pain. ${ }^{23}$ Peripheral nerve stimulation, a minimally-invasive procedure, may be useful in cases of chronic low back pain that do not respond to other measures, although the evidence supporting it is not conclusive, and it is not effective for pain that radiates into the leg. ${ }^{24}$

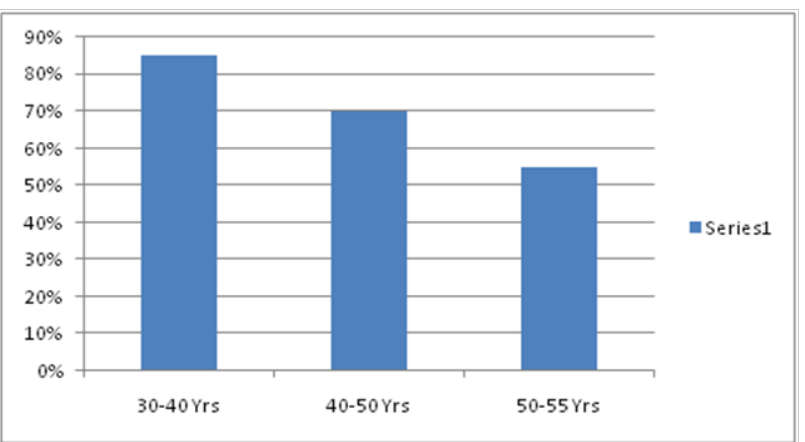

Figure I Graphical representation for cure of patients after the treatment of Physiotherapy.

\section{Conclusion}

It is concluded that lumber stress and strain occurs in young adults with maximum age incidence between 35 to 45 years, male were more sufferer than female. Manual workers suffer more often than sedentary professional. Common presenting features were pain with spasm, tenderness, limited lumber movement and decrease function. The result of the physiotherapy management for postural low back pain due to ligament stress and strain in a professional group of middle aged population was very much satisfactory particularly in acute cases. 


\section{Acknowledgments}

None.

\section{Conflicts of interest}

None.

\section{References}

1. Deyo RA, Mirza SK, Martin BI. Back pain prevalence and visit rates: estimates from U.S. national surveys. Spine (Phila Pa 1976). 2006;31(23):2724-2727.

2. Ferreira GD, Silva MC, Rombaldi AJ, et al. Prevalência de dor nas costas e fatores associados em adultos do sul do Brasil: estudo de base populacional. Rev Bras Fisioter. 2011;15(1):31-36.

3. Andersson G. Epidemiological features of chronic low-back pain. Lancet. 1999;354(9178):581-585.

4. Srinivas SV, Deyo RA, Berger ZD. Application of "Less Is More" to Low Back Pain. Arch Intern Med. 2012;172(13):1016-1020.

5. Clinical Standards Adivsory Group. Epidemiology review: the epidemiology and cost of back pain. Soc Sci Med. 1996;42(4):561-563.

6. Schneider S, Mohnen SM, Schiltenwolf SM, et al. Co morbidity of low back pain: representative outcome of a national health study in the Federal Republic of Germany. Eur J Pain. 2007;11(4):387-397.

7. Altinel L, Kose KC, Ergan V, et al. The prevalence of low back pain and risk factors among adult population in Afyon region, Turkey. Acta Orthop Traumatol Turc. 2008;42(5):328-333.

8. Leclerc A, Gourmelen J, Chastang JF, et al. Level of education and back pain in France: the role of demographic, lifestyle and physical work factors. Int Arch Occup Environ Health. 2009;82(5):643-652.

9. Nahar BN. Prevalence of low back pain and risk factors among car drivers. South East Asia Journal of Public Health. 2012;2(1):60-63.

10. Sprouse R. Treatment: current treatment recommendations for acute and chronic undifferentiated low back pain. Prim Care. 2012;39(3):481-486.

11. Koes BW, van Tulder M, Lin CW, et al. An updated overview of clinical guidelines for the management of non-specific low back pain in primary care. European Spine Journal. 2010;19(12):2075-2094.
12. Casazza BA. Diagnosis and treatment of acute low back pain. American family physician. 2012;85(4):343-350.

13. Momsen AM, Rasmussen JO, Nielsen CV, et al. Multidisciplinary team care in rehabilitation: an overview of reviews. $J$ Rehabil Med. 2012;44(11):901-912.

14. Hendrick P, Milosavljevic S, Hale L, et al. The relationship between physical activity and low back pain outcomes: a systematic review of observational studies. Eur Spine J. 2011;20(3):464-474.

15. Hendrick P, Te Wake AM, Tikkisetty AS, et al. The effectiveness of walking as an intervention for low back pain: a systematic review. Eur Spine J. 2010;19(10):1613-1620.

16. French SD, Cameron M, Walker BF, et al. Superficial heat or cold for low back pain. Cochrane Database of Systematic Reviews. 2006;25(1):CD004750.

17. van Middelkoop M, Rubinstein SM, Kuijpers T, et al. A systematic review on the effectiveness of physical and rehabilitation interventions for chronic non-specific low back pain. Eur Spine. 2011;20(1):19-39.

18. Guild DG. Mechanical therapy for low back pain. Prim Care. 201239(3):511-516.

19. Smith C, Grimmer-Somers K. The treatment effect of exercise programmes for chronic low back pain. $J$ Eval Clin Pract. 201016(3):484-491.

20. van Middelkoop M, Rubinstein SM, Verhagen AP, et al. Exercise therapy for chronic nonspecific low-back pain. Best Pract Res Clin Rheumatol. 2010;24(2):193-204.

21. Woodman JP, Moore NR. Evidence for the effectiveness of Alexander Technique lessons in medical and health-related conditions: a systematic review. Int J clin pract. 2012;66(1):98-112.

22. Posadzki P, Ernst E. Yoga for low back pain: a systematic review of randomized clinical trials. Clin Rheumatol. 2011;30(9):1257-1262.

23. Dubinsky RM, Miyasaki J. Assessment: Efficacy of transcutaneous electric nerve stimulation in the treatment of pain in neurologic disorders (an evidence-based review): Report of the Therapeutics and Technology Assessment Subcommittee of the American Academy of Neurology. Neurology. 2009;74(2):173-176.

24. Nizard J, Raoul S, Nguyen JP, et al. Invasive stimulation therapies for the treatment of refractory pain. Discov Med. 2012;14(77):237-246. 